\title{
Smart cities: A case study in waste monitoring and management
}

\author{
Andre Castro Lundin \\ Technical University of Denmark \\ 426 Produktionstorvet 2800 Lyngby, Denmark \\ andre.cl@hotmail.com
}

\author{
Ali Gurcan Ozkil \\ Technical University of Denmark \\ 426 Produktionstorvet 2800 Lyngby, Denmark \\ alioddtu.dk
}

\author{
Jakob Schuldt-Jensen \\ IBM Denmark \\ Kongevejen 495B, 2840 Holte \\ js jensen@dk. ibm.com
}

\begin{abstract}
This paper explores the potential of employing sensor enabled solutions to improve on waste monitoring and collection in public trash bins. Through a user-centered design approach, an inexpensive monitoring system developed and tested in pilot study. The system consists of wireless nodes that use ultrasonic sensors to measure the empty space in the bins, a sensor gateway that is based on Long Rage Wide Area Network (LoRaWAN) protocol and cloud-based back/front end for data collection, analysis and visualization. The system was evaluated through a pilot test, where six outdoor trash bins were remotely monitored at a university campus and a number of stakeholders were observed and interviewed. The results show that the existing technologies are mature enough to be able to develop and implement inexpensive add-on sensors to exiting trash bins, and employing such a system can provide the necessary insights to optimize waste collection processes, to avoid overfilled bins, and to improve the experience of the citizens.
\end{abstract}

\section{Introduction}

During the last century the world population has been quadrupled, and there has been major relocations from rural to urban areas. Today $50 \%$ of the world's population inhabit cities and this number is expected to reach $70 \%$ by $2050[21]$. As the World's population shift towards urban areas, cities have been facing complex problems in resource management, health, pollution, traffic and waste management[18]. In parallel, the recent years has witnessed the rise of the 'smart cities', where these wicked challenges[13, 46] are tackled with technology driven solutions.

This paper presents a case study in waste monitoring and

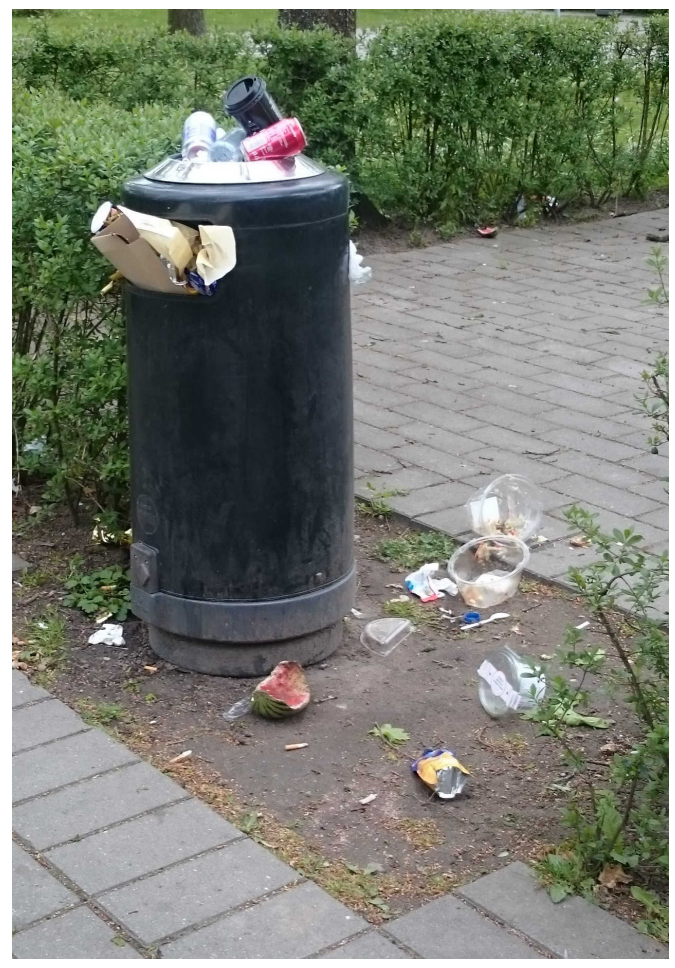

Figure 1. Unmonitored trash bin during the pilot test

management of public trash bins. Smart city technologies is an emerging topic and there is still a lack standards, methodologies and best practices. In this regard, this study has two aims:

- To understand the needs of the stakeholders and identify requirements

- To design internet-of-things based system to monitor public trash bins and evaluate its usage. 
From collection to processing and disposal; waste management is a major issue for urban cities. One of the most challenging areas that cities strive to improve is the effective use of public trash bins. According to the Danish Environmental Protection Agency, it costs $15 \mathrm{DKK}(\$ 3)$ to pick up a bottle from the floor instead of it being in the bin. The cost for picking up a piece of gum is so high (10DKK/ \$2) that some of the municipalities have stopped cleaning them off the streets [2]. Beyond the economical challenges, inadequate waste management in urban cities can also represent a vast annoyance for the citizens. For example, one third of complaints submitted to the mobile application to provide feedback from the citizens to the municipality of the city of Copenhagen were about overfilled bins [43].

A user-centered design approach is adopted in the design and development of the system. In addition to the review of the relevant literature in smart cities and smart waste management systems; we have interviewed a number of stakeholders and observed trash collection routines in Situ. Next, we have designed a system based on the elicited requirements. The system consists of a network of small, battery powered wireless sensors that are retrofitted to existing trash bins, a cloud based back-end that aggregates data from the sensors and a front-end that visualizes the utilization levels of the bins. The results show that the system can provide a data-driven approach to waste collection and management; both as real-time feedback and long-term insights that can be derived from use-patterns and contextual data.

The rest of the paper is organised as follows. First, we provide an overview of the existing work in smart city technologies and smart waste management. Next, we identify the needs and wishes of the stakeholders through interviews and observations, and present the designed system. Section 4 outlines the testing of the prototype and provides the results of the experiments. Finally, the implications of the case study are discussed in the discussion and the conclusion section provides the final remarks and directions for future work.

\section{Theoretical Background}

The term "smart city" first appeared in 1998 [45] and has been increasing popular in the recent years. Due to its interdisciplinary nature, definitions of the term vary with the context of use - from construction, energy, social sciences to transportation, urbanship and information and communication technologies (ICT) [11]. As a result, there is still not a clear and consistent understanding of the concept among practitioners and academia[18].

A number of researches have provided holistic overviews of the term and its use context [10, 18, 36, 15, 30, 11]. Giffinger et al. defines the smart city as "a city well performing in a forward-looking way, built on the smart combination of endowments and activities of self-decisive, in- dependent and aware citizens" and identifies six application domains (economy, people, governance, mobility, environment and living) [26]. Sanseverino underlines that the ultimate goal of the smart cities is to increase the quality of life ,"where citizens are involved as main actors in decision processes" [41], and claims that modern ICT is an integral part of this participatory governance [42].

From the technological point of view, smart cities are not only about automating routine functions, but also monitoring, understanding, analyzing and planning the city and processes within. In this regard, Picon refers to the intelligence of cities where intelligence is defined in the sense of the ability to learn, understand and reason using ICT technologies [39]. Smart cities empower data-driven decision making processes, which in-turn can improve efficiency, equity and quality of life for the smart city's citizens, in real time. [34]

Widespread and inexpensive availability of cloud computing services, rapid penetration of smart phones in urban populations as well as the rise of Internet of Things (IoT) in the form of deployment of a variety of sensors drive smart city technologies that offer new application domains in city planning and operations. IoT refer the use of network protocols to form a universal network of interconnected things, that are not necessarily considered as computers. It is projected that there will be 34 billion connected things in the world in 2020 [14], and the IoT will dominate the smart city technologies.

\subsection{Smart Waste Management}

Waste management has not been the exception of processes optimized and automated with smart city technologies, and as such, the field of waste management has been subject to large innovations using ICT. According to Lawrance et al., smart technologies will have their main impact on collection, processing, energy recovery and disposal phases of the traditional waste management value chain[32].

Waste management has been a topic of interest in operations research and it has been demonstrated that optimized route planning and scheduling in waste collection can lead to significant cost reductions [38]. Consequently, route optimization has been the main motivation for developing smart waste collection systems. One of the earlier works in smart bin monitoring is presented in [19], where authors present a radio frequency identification (RFID) based monitoring solution. The system utilizes load sensors to estimate the accumulated weight in the trash bins, and relays the data to collectors' pocket PC's (PDA). Collected data is then uploaded to an online database for further processing and analysis.

RFID-based waste collection is also discussed in [48], with a focus potential applications of smart bins in use- 


\begin{tabular}{|l|c|c|}
\hline Solution & Test stage & in Market \\
\hline \hline Top-k[9] & $\checkmark$ & \\
Robust[7] & $\checkmark$ & \\
Tracking[33] & $\checkmark$ & \\
Smart Waste[27] & $\checkmark$ & \\
Priority[8] & $\checkmark$ & \\
Big belly[40] & & $\checkmark$ \\
Enevo [3] & & $\checkmark$ \\
SmartBin & & $\checkmark$ \\
SENSdumpster[5] & & $\checkmark$ \\
\hline
\end{tabular}

Table 1. Stage of solutions (names abbreviated)

based business models (pay-as-you-throw / PAYT) for waste management. In [28], authors present an IoT based smart garbage system, that utilizes PAYT model for food waste management. The system proposes custom-designed household garbage bins that are equipped with load sensors and cellular Internet modules. The system is tested through a pilot study in Seoul, Korea, and authors underline that the power consumption (battery-based operation) is the main trade-off of the system.

In addition to their real-time and on-site uses, the data generated by smart trash bins are also used for developing decision support systems. In [6], authors emphasize that "an efficient, cost effective and environment friendly solution for real time bin status monitoring, collection and transportation of municipal solid waste is still a major challenge to the local municipal authorities" and propose a theoretical model using rule based decision algorithms. In [35], a support system that combines IoT technologies and surveillance systems is proposed, with the goal of improving the efficiency of collection routines. Cavdar et al. further expands the smart bin concept and proposes an IoT based architecture in [16], which consists of robotic waste collection vehicles and custom-designed waste containers.

\subsection{Commercially available solutions}

In addition to the smart trash bins that are presented in research context, there are also a few solutions on the market that are either commercially available or in testing phase. Table 1 shows the different solutions and the stages they have reached. Among the existing smart trash bins; BigBelly [40] stands out, as it can also compress the trash that is collected inside the bin, using solar powered motors. While it is the most widely available smart trash bin that is on the market, high capital investment costs ( $\$ 4000$ per bin [23]) hinders it's wider adoption.

The system presented in this paper differs from the above-mentioned smart waste management and collection solutions, mainly in terms of the design approach. Many of the solutions presented in the research literature are designed in a technology-driven way, where the needs and re- quirements are not discussed in detail( e.g. [6, 35]) and a new and interesting technology (e.g. RFID, [19, 48]) dominates the final design. While there are a few commercially available solutions on the market, they are regarded as expensive and high-end solutions [23, 37] and their measured impact is yet to be reported.

\section{Methodology}

Our design approach is based on engineering design methodology [44], and applies the user-centred design principles[22]. The design process starts with identifying the needs, deriving requirements, conceptualisation of the solutions, evaluating the concepts and finalizing the design.

\subsection{Identification of needs and challenges}

Smart waste management is an emerging topic that attracts the interest of many public and private entities. In order to better understand the existing challenges and the needs of different stakeholders, we have conducted interviews with companies working in waste collection, management and smart cities, city officials from different municipalities and a number of private citizens. Except one (in Finland), all interviews were conducted in Denmark.

All interviewees acknowledge that collection of waste from public bins is a costly and increasingly complex issue. For example, the municipality of Copenhagen went over its waste collection budget by 100 million DKK ( $\$ 15$ million ) in the last four years[47][4]. This problem is currently being addressed by hiring more collectors, which is a solution to a symptom of the problem. On the other hand, it is also acknowledged that there is a need for a better understanding of how these public trash bins are used, and how their utilization can be optimized. There are even some manual monitoring experiments conducted by the municipality of Copenhagen - approximately $\$ 50,000$ yearly budget is allocated to hire a number of people to physically count and record the trash being thrown in the bins.

All of the interviewees believe that the current state of ICT is mature enough to be able to monitor trash bins. On the other hand, they have expressed a number of concerns that are economic, managerial, societal and political in their nature. Following list summarizes these issues:

- Many possible clients (municipalities) have already a large number of bins, so the high price for new smart bins discourage them.

- It is much simpler to get funding for one more waste collector (job creation) when it is needed, than for a large implementation of an advanced system.

- As in the case of solutions that require high capital investment, there is also a negative attitude towards solutions that are based on a subscription. 
- Though most solutions ensure a durability of around a decade, clients are sceptical of these claims, as they see vandalism and theft as big threats.

- Different entities have different rules in regards to trash collection. Context is not accounted for in existing solutions. Eventhough there has been a research focused on this issue [20], it is not yet taken into account commercially.

- Many public entities are looking for open source solutions, that they can easily build on top of, modify or port to other solutions. Most existing solutions are proprietary.

- Not only in waste collection, but in many smart city solutions, the individual solutions have their own systems. This is not viable in the long term and the need for a unified platform is reflected in a number of scientific papers[29][12]. Some larger companies have developed such platforms (IBM, Cisco and Siemens) but certain clients require that together with the previous mentioned element.

- Current solutions account for metrics that are important to management (time, price, fuel consumption, etc.) but do not include metrics that are important to collectors and users (smell, user experience, cleanliness).

- Management usually believes that no significant optimization is possible due to various reasons (many bins, short distances, etc.). Even if it is, they question the fact that it might be worth the investment.

- There is a reluctance to the possibility of having to let go part of the workforce (especially in public entities).

- Many managers of large waste collection areas are not aware of existing solutions.

- Implementing such a system means more work for management during the initial stage, which discourages many.

\subsection{Requirements}

Many of the existing solutions provide partial solutions to the issues mentioned above. In addition to the core requirement - being able to monitor trash levels in individual bins- we have identified the following three major requirements:

- Low cost sensor: Replacing the existing trash bins with the smart ones is not a viable option for most of the public entities, therefore an add-on sensor solution is required. The sensor node needs to be cheap enough so that if it is damaged or lost it won't be a big economic issue to replace it. Based on our interviews, 500DKK, or roughly $\$ 100$ per bin is identified to be appropriate for the price of the sensor node. It is clear that the most important obstacle to widespread implementation of smart collection systems is the high capital investment cost. Current add-on smart sensors available on the market cost as much as the bins themselves. Though most market solutions promise that the sensors will have an economic life of up to 10 years, the interviews conducted showed that every single manager in both the private and public trash collections sector is fully aware that this would not be the case. Bins are often set on fire or blown up with fireworks. They are treated really harshly and the threat of theft of mounted sensors is high.

- Simplicity: High tech solutions are rather disadvantageous. Having a very advanced and expensive device in a bin brings no value to the client (municipalities) nor the user of public areas. Therefore a simple solution is required seeing how the value does not come from the sensor itself, but from using the trash level data. Related to this, using off the shelf components can help to maintain simplicity as well as keeping the costs down.

- Open/transparent system: There is a lot of focus on open data, open source and compatibility. Municipalities are looking for solutions that can work together and where they have the freedom to switch between different systems without major difficulties. This could for example mean that a municipality might choose to implement other sensors, or use the sensors on another platform, or even further develop the systems themselves.

\subsection{System design}

Based on these requirements, we have developed an addon sensor system, that is simple to install, inexpensive and based on open standards. The system consists of sensor nodes, gateways, a cloud based backend for data collection and a front-end for visualisation for analytics 2 .

\subsubsection{Sensor Nodes}

Sensor nodes are simple devices that can measure the empty space in the trash bins using ultrasonic sensors, and later transmit the data to the backend. Wireless communication is one of the key aspects of the design of the sensor node, and the overall topology of the system. There exists a number of different technologies, that offer high bandwidth (Wifi), long range (GSM/CDMA), low power (Bluetooth low energy (BLE)), or mesh-network capabilities (ZigBee). While 


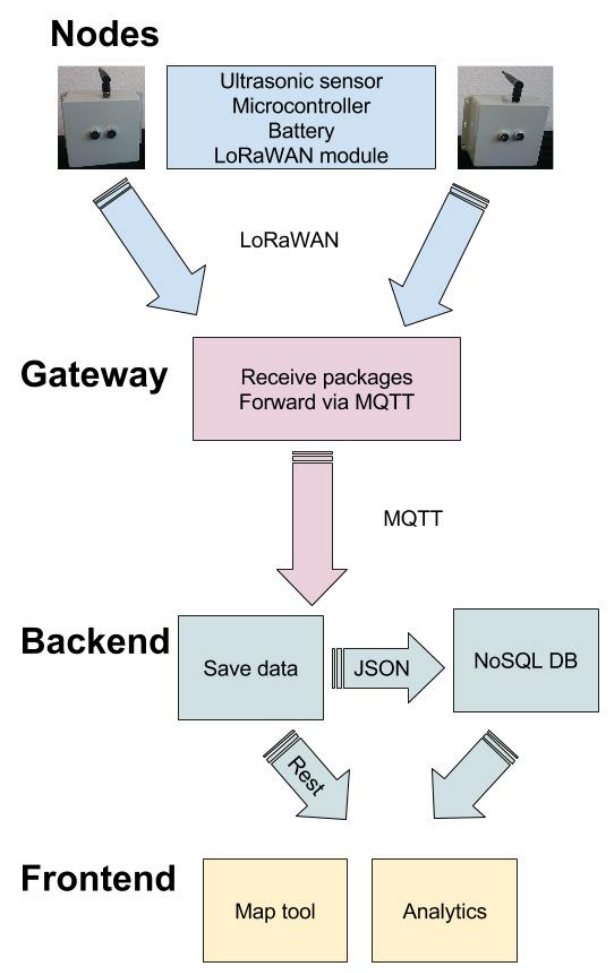

Figure 2. System architecture

all these technologies are considered to be mature, none of them are optimal for IoT applications. In this regard, our sensor nodes utilize a new technology that is designed for long range wide area networks (LoRaWAN). The reason to use LoRaWAN is its long range (in comparison to bluetooth and $\mathrm{WiFi}$ ), low power consumption and price (in comparison GSM network solutions). This also allows for easier scalability as one gateway can handle thousands of nodes within a few kilometers radius [17]. Despite lacking maturity[1], LoRaWAN is gaining a lot of momentum and it is expected to dominate IoT solutions in the future [24].

\subsubsection{Gateway}

LoRaWan networks are hub based star topologies, and the gateway is the physical unit that receives the data packages from the nodes and forwards it to the backend system. The gateway consists of a LoRaWan concentrator(iC880A) that works in the $868 \mathrm{Mhz}$ frequency band, and a Internet connected single board computer. We have used the open source The Things Network[25] to forward the data packages to the backend.

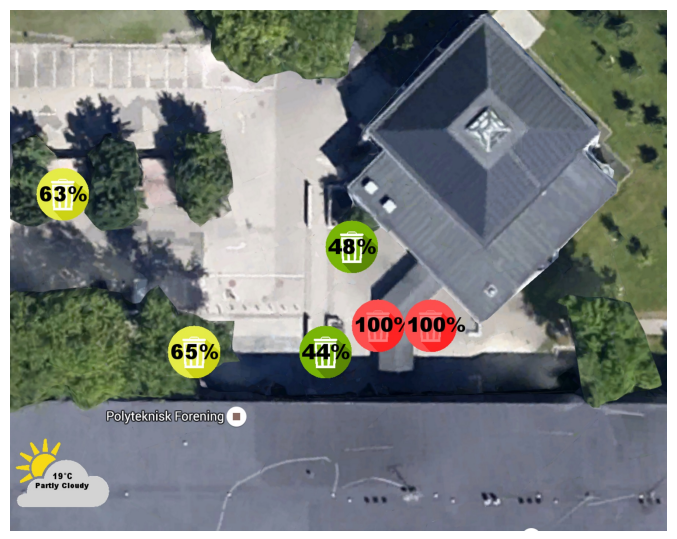

Figure 3. Map view provides shows the location and the current state (percent full) of the bins

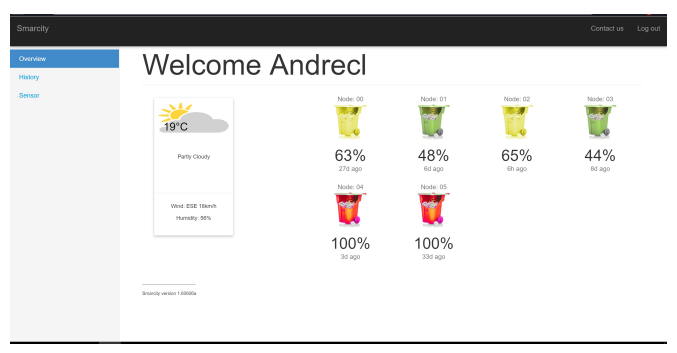

Figure 4. Overview screen provides a quick visualization all bins

\subsubsection{Backend}

The backend consists of a cloud-based app that receive data from the nodes using the MQTT (Message Queue Telemetry Transport) protocol. MQTT is lightweight and requires limited network bandwidth, making it optimal for such short messages. The data is stored in a NoSQL database, which allows flexibility to test out what data might be useful to send and store without major changes to the database. This also allows the implementation of the solution into any existing management systems.

\subsubsection{Frontend}

Finally, there is a secure and web based front-end that allows the users to access a map tool (see Figure 3 pas well as overview screens (see Figure 4) and some analytical tools (see Figures 5 and 6 . The front-end is designed to provide an accessible interface for mobile devices as well as computer screens.

\section{Evaluation}

In order to evaluate the system and gather insights about its potential uses and impacts, we have built a number of sensor nodes and designed a pilot study, in collaboration with the Campus Service at the Technical University of 


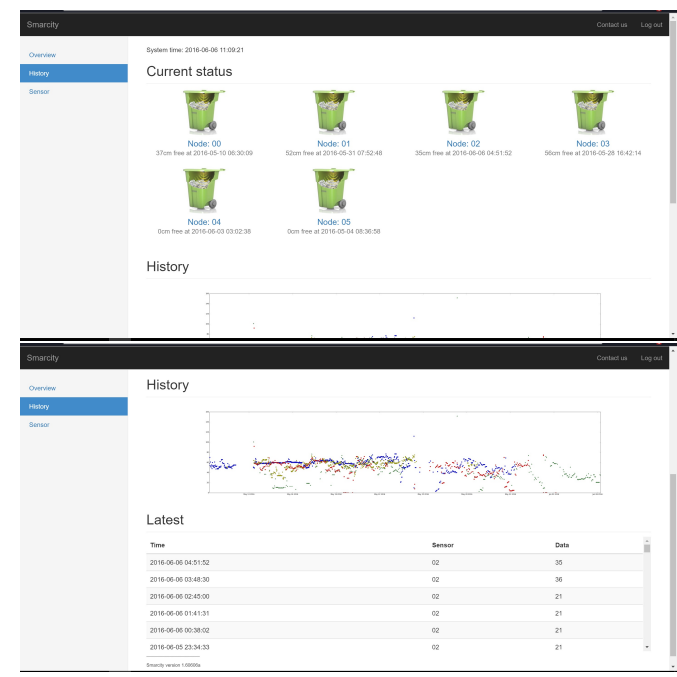

Figure 5. History screen Visualization of all historical gathered data.

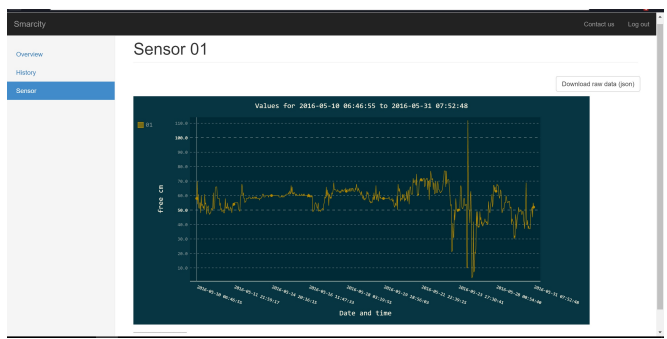

Figure 6. Analytics and data for a specific sensor

Denmark. Based on the interviews with the managers and trash collectors, an outdoor area between the central university building and the concert/event hall. The selection was made based on the following factors:

- Busy all year round, regardless of exam periods or vacations.

- Close proximity to the cafeteria, the concert hall and a number of offices, meaning a variety of trash is thrown there.

- Proximity to the concert hall means that there are often inebriated subjects after events.

- Impromptu gatherings are known to happen in the area.

Sensor nodes are mounted on top of the bins, with downward facing ultrasonic sensors, that measure the distance to the nearest object in the bin. Before the pilot study, sensors were calibrated in the lab environment; and the empty space in the trash bins were derived as a function of the measured distance.

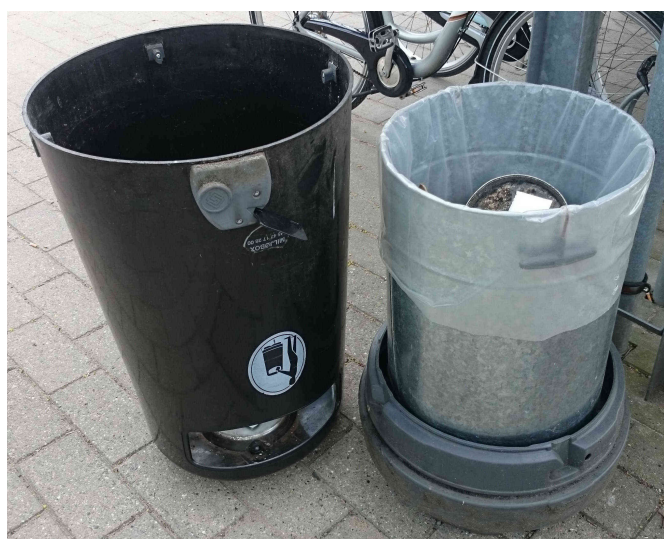

Figure 7. Existing trash bins are employed in the pilot test

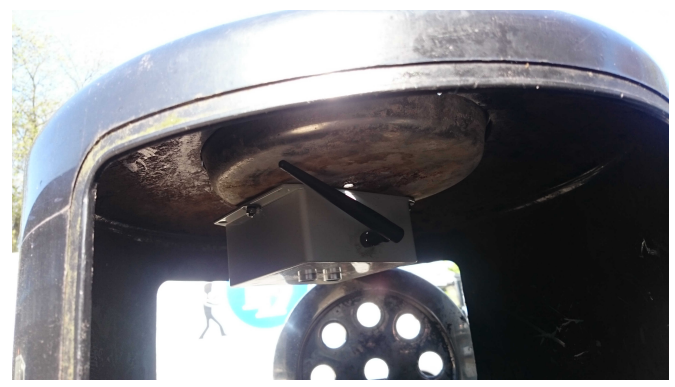

Figure 8. Sensor nodes are attached to the bins using simple mechanical fasteners.

Six bins were allocated by the Campus Service for the pilot study (see Figures 7 and 8 . Due to issues with the gateway, only 4 out of the 6 bins sent significant amount of data for analysis.Over 2000 data points were collected during the 19-day duration of the pilot study. ( Figure 9).

In addition the quantitative analysis of the collected data, a significant focus was put on qualitative testing by means of following the actors[31], observations and interviews. This was important for a number of reasons, as it allowed understanding the context behind the findings, helped to assess the reliability of the data, allowed to observe the environment and behavior of the involved parties (waste collectors and users of the public areas, and provided the opportunity to interview the users during use.

\subsection{Results}

The data was analysed in accordance to the observations during the pilot test (see Figure 10).

Bins 01, 03 and 04 are located in an area where it is common for smokers to stand. Bin 02 was filled very quickly during the weekends, from visual observation it was clear that this was due to being located at an entry point to the building where students work all seven days of the week. This meant that the bin usually needed to be emptied on 


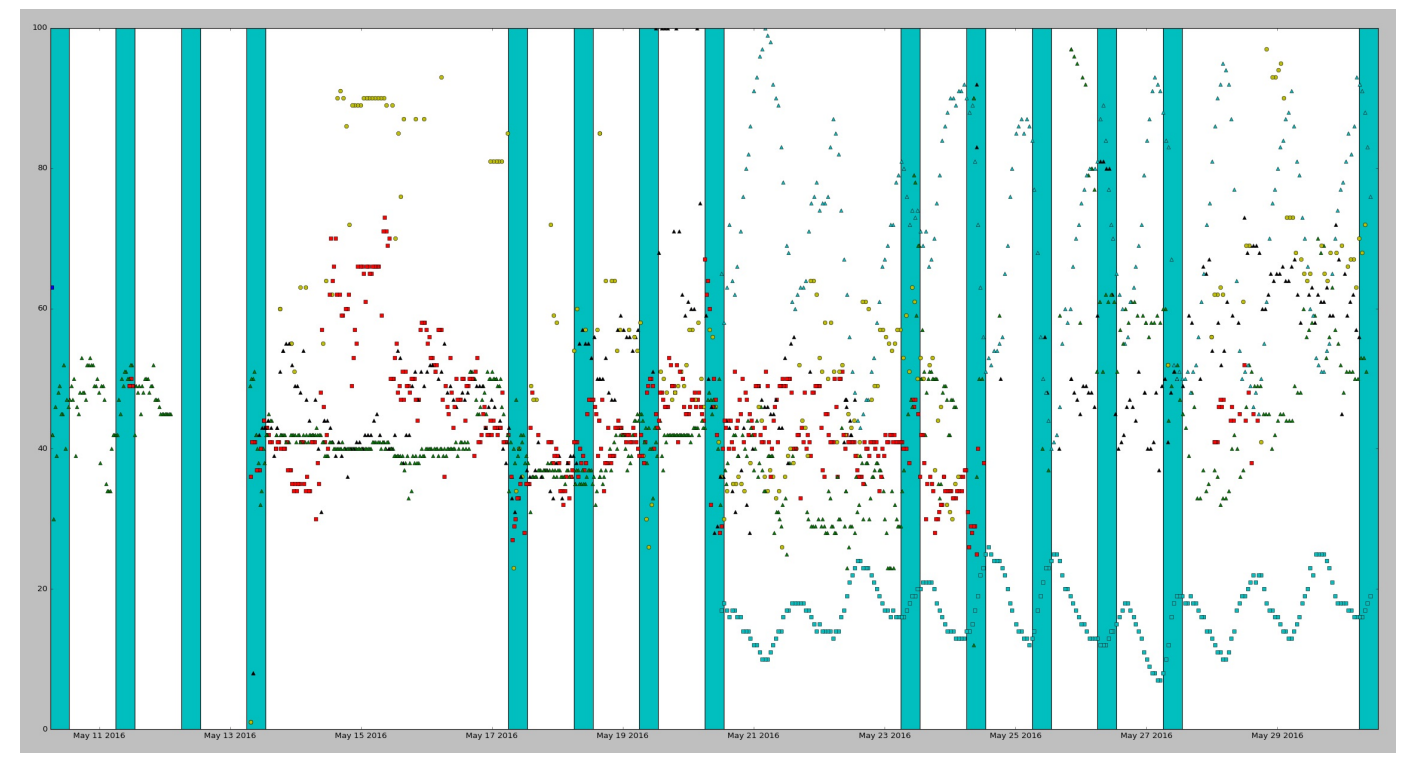

Figure 9. Over 2000 data points were collected during the pilot study (Percentage of the trash/empty space vs time). Bins are normally emptied during work hours (vertical bars). Temperature and humidity data is also collected during the study (top/bottom curves)

Monday mornings.

Bin 04 was the closest to an outdoor sitting space that is frequented for lunch by cafeteria workers. Therefore it was quickly filled after the lunch hours during work days (Monday-Friday).

Bins 01 and 03 , though very close to the other two, were used far less. This is interesting, as it shows that users are not willing to walk a few meters towards a bin even though it is empty. Instead they prefer the closest bin, despite its state.

From observation it was clear that the bins were subjected to a lot of physical abuse (being kicked around, tipped over) and very efficiently, but violently, emptied by removing the lid where the sensor was mounted. In addition, the biggest worry of the collectors was the sensors ability to withstand rain and humidity. The sensors survived both the physical abuse and a number of rainy and humid days during the 19 day period.

\section{Discussion}

Despite it's limitations in terms of duration and scale; the pilot test provides a proof-of-concept solution that complies with the requirements, bridging the gap between the wishes of collectors, management and users.

The hardware was kept at slightly under 500DKK $(\$ 100)$ per bin for the prototype sensor nodes that are build using off-the-shelf modules. The main software blocks of the system are based upon open source frameworks, and the focus on developing a minimum viable product ensured simplicity. The system in itself is scalable, as the nodes are based on open hardware and the backend relies on standardized cloud computing services.

The major selling point for smart collection systems has been that they offer a major saving in regards to emptying the bins[7][9], by ensuring that a bin is always emptied when it is full, rather than half full. In reality, the pilot study proved that the optimization of waste collection and management is a complex issue, which can not be reduced to a single parameter.

In regards to densely populated areas where trash bins are placed close to each other, emptying only the full bins do not provide a significant benefit over emptying all the bins at the same time. The most important goal is to keep public areas clean and free of foul smells. The waste collectors only see the data provided by the system (such as 3 ) useful if they can monitor the isolated bins that are far away. Management on the other hand sees it as a great tool to detect the unexpected, such as impromptu parties, that suddenly generate abnormal levels of trash.

\subsection{Insights}

After spending a month in interviews and observing the work done by collectors, there are three very strong arguments in favor of the proposed smart waste monitoring system:

- Translatable collector knowledge: Any experienced collector knows the patterns of trash in different bins. As long as the collector and the system know the same factors, there is little that predictive analysis can offer. On the other hand, in sick days, or when a collector 

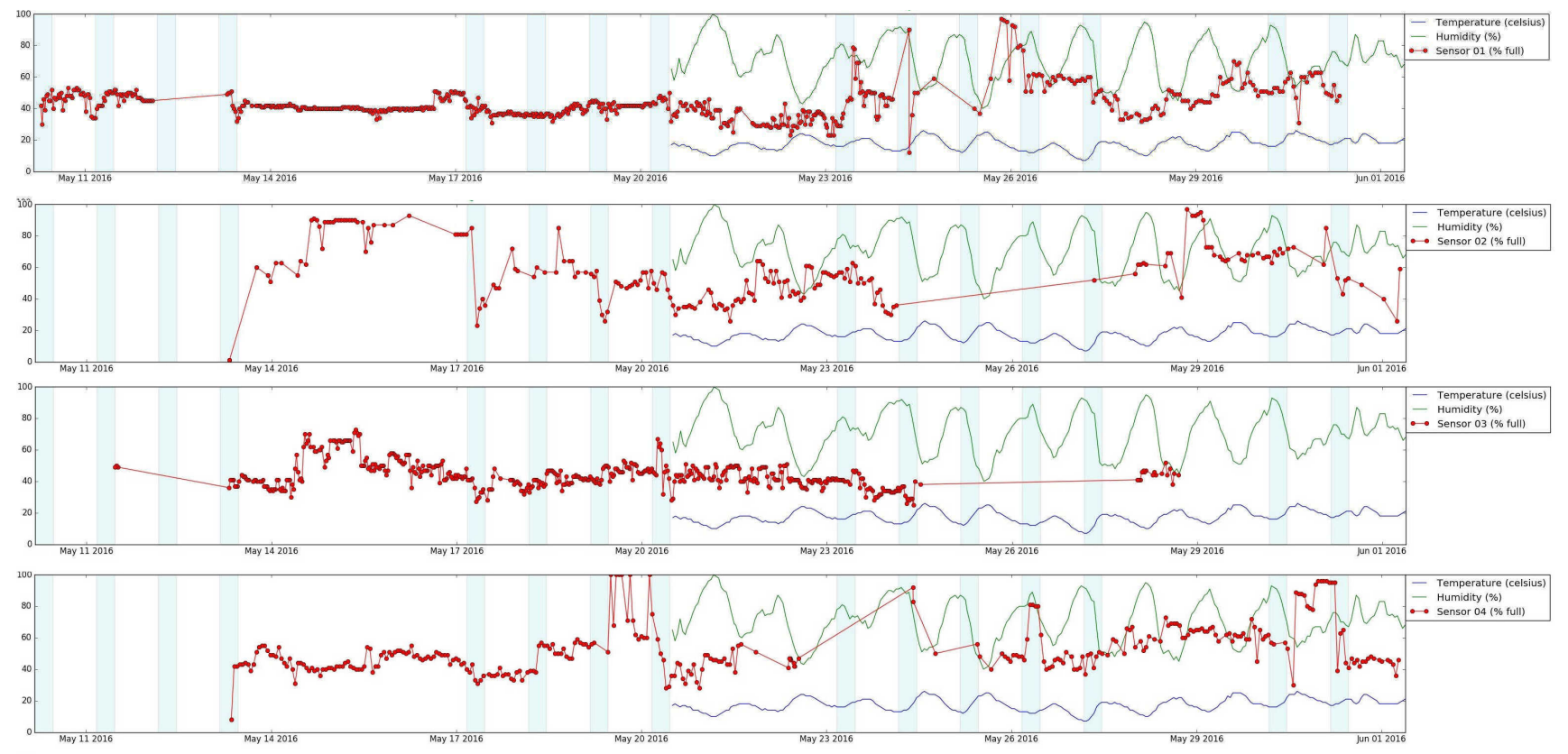

Figure 10. Bins 01, 02, 03 and 04. Axes: Measure/Time. Bin 01: Emptied at the beginning (May 10) of the data gathering process and 2 weeks later (May 24). Bin 02: Emptied after long weekends (May 17 and May 31). Bin 03: Bin that observed the least activity, in spite of its proximity to bin 04. Bin 04: The bin that experienced the most activity, due to its proximity to outdoors eating area. Was emptied once per week (May 20, May 24, May 26 and May 31).

retires/quits, the obtained knowledge is lost. The new collector will have to figure out the system by himself.

- Improved user experience: Monitoring trash levels can provide actionable data, and the negative effects of forseen situations, such as impromptu parties or gatherings, can be minimized. These are the big issues for management, as these rare occurrences cause overfilled bins and complaints from users. By warning the collectors when the bin is about to reach its capacity, the system can help improve the overall experience of the users. This is a very important, yet much ignored issue; and a smart monitoring system allows for a proactive rather than a reactive approach.

- Bin placement optimization: There is a big potential in terms of optimal placement of the trash bins in public spaces. Instead of relying on prior experience and intuitions, a data driven approach can be utilized to optimize the number and the placement of trash bins. For example, after the pilot study was presented to the Campus Service management, some of the underutilized trash bins have been relocated to more densely used locations.

\section{Conclusion}

This paper presented a smart monitoring system for public trash cans.The user-centered design approach was used to understand the needs of the users, derive the requirements and develop the system. Continuous involvement of the stakeholders during design phase assured the alignment between design objectives and the results of the pilot study.

The system was evaluated by combining quantitative data, that is collected from the wireless sensor network and the qualitative data that is based on observations and interviews. One of the main requirements for the design was setting $\$ 100$ as the maximum price per sensor/bin; making cost as the key challenge for a smart trash collection solution. This price limit was respected throughout the study, with the potential of lowering it substantially by designing a more integrated solution and with the economies of scale.

The project also showed that the most important argument for the implementation of a smart collection system is the ability to improve the service quality for users (citizens) and the work experience for collectors, rather than the possibility of cost reductions. Such a system should not replace the knowledge that collectors have of an area, but instead build on top of it, allowing them to better assess situations. Both municipalities and private contractors that do trash collection work towards one goal: Improving the quality of experience of users in the area. It is highlighted that, implementing a smart trash monitoring system will require commitment and financial investment, and the feasilibity of the solutions depend on how much user satisfaction is worth to these parties. 
With that in mind, there are two interesting paths to further investigate: How to transfer the knowledge from current collectors to new collectors and if it is possible to fix the overfilled bins problem by going to the root of the problem and trying to change the users behaviour.

\subsection{Future Work}

During the pilot test it was clear that users are unwilling to walk towards another empty bin when a bin is overfilled, even if it is within their sight. Gamification and nudging has been already used in traditional waste collection settings, and we believe that their utilization should be further explored in smart waste management.

In regards to the sensor nodes, an integrated board can be designed to reduce the manufacturing costs and significantly decrease the physical footprint. Finally, the system can greatly benefit from adding a volatile organic compound or gas sensors; which can provide an estimation of the odours concentrated in the trash bin and provide a dimension in analytics.

\section{References}

[1] Lorawan specification 1.0, lora alliance, 2015. available at http://lora-alliance.org/

[2] Aarhus dropper at fjerne tyggegummi fra fortov og veje, 2016. available at http://stiften.dk/indland/ aarhus-dropper-at-fjerne-tyggegummi

[3] Enevo - waste collection for smart cities, 2016. available at http://enevo.com

[4] Koebenhavn har tabt 100 millioner kroner paa at samle skrald ind, 2016. available at http://goo.gl/Kmvrlr.

[5] Sensdumpster- sayme wireless sensor networks, 2016. available at http: / / sayme.es.

[6] M. A. Al Mamun, M. Hannan, A. Hussain, and H. Basri. Theoretical model and implementation of a real time intelligent bin status monitoring system using rule based decision algorithms. Expert Systems with Applications, 48:7688, 2016.

[7] T. Anagnostopoulos. Robust Waste Collection exploiting Cost Efficiency of loT potentiality in Smart Cities. (April):79, 2015.

[8] T. Anagnostopoulos, K. Kolomvatsos, C. Anagnostopoulos, A. Zaslavsky, and S. Hadjiefthymiades. Assessing dynamic models for high priority waste collection in smart cities. Journal of Systems and Software, 110:178-192, 2015.

[9] T. Anagnostopoulos, A. Zaslavsy, A. Medvedev, and S. Khoruzhnicov. Top - k Query based Dynamic Scheduling for IoTenabled Smart City Waste Collection. (JUNE):50-55, 2015.

[10] L. Anthopoulos and P. Fitsilis. Using classification and roadmapping techniques for smart city viabilitys realization. Electronic Journal of e-Government, 11(1):326-336, 2013.

[11] L. G. Anthopoulos. Understanding the Smart City Domain: A Literature Review. Public administration and information technology2, (8), 2015.
[12] S. Balandin, S. Andreev, and Y. Koucheryavy. Internet of Things, Smart Spaces, and Next Generation Networks and Systems. Number August. 2014.

[13] R. Buchanan. Wicked problems in design thinking. Design issues, 8(2):5-21, 1992.

[14] J. Camhi. Business insider intelligence projects 34 billion devices will be connected by 2020,2016 . available at $h t t p:$ //goo.gl/chetVd

[15] A. Caragliu, C. Del Bo, and P. Nijkamp. Smart cities in europe. Journal of urban technology, 18(2):65-82, 2011.

[16] K. Cavdar, M. Koroglu, and B. Akyildiz. Design and implementation of a smart solid waste collection system. International Journal of Environmental Science and Technology, 13(6):1553-1562, 2016.

[17] M. Centenaro, L. Vangelista, A. Zanella, and M. Zorzi. Long-Range Communications in Unlicensed Bands: the Rising Stars in the IoTand Smart City Scenarios. IEEE Wireless Communications, 23, October 2016.

[18] H. Chourabi, T. Nam, S. Walker, J. R. Gil-Garcia, S. Mellouli, K. Nahon, T. A. Pardo, and H. J. Scholl. Understanding smart cities: An integrative framework. In System Science (HICSS), 2012 45th Hawaii International Conference on, pages 2289-2297. IEEE, 2012.

[19] B. Chowdhury and M. U. Chowdhury. Rfid-based real-time smart waste management system. In Telecommunication Networks and Applications Conference, 2007. ATNAC 2007. Australasian, pages 175-180. IEEE, 2007.

[20] L. Coetzee, A. Smith, A. E. Rubalcava, A. A. Corici, T. Magedanz, R. Steinke, M. Catalan, J. Paradells, H. Madhoo, T. Willemse, J. Mwangama, N. Mukudu, N. Ventura, M. Barros, and A. Gavras. TRESCIMO: European union and South African Smart City contextual dimensions. IEEE World Forum on Internet of Things, WF-IoT 2015 - Proceedings, pages 770-776, 2016.

[21] D. Constantino. Urban Smartness: Tools and Experiences. Sxl - Springer for Innovation, (12), 2014.

[22] I. DIS. 9241-210: 2010. ergonomics of human system interaction-part 210: Human-centred design for interactive systems. International Standardization Organization (ISO). Switzerland, 2009.

[23] E. Elveru, D. Daws, T. Hammes, and K. McKinney. Taking the green initiative. Ethos, 2012(3):24-27, 2015.

[24] N. Franck. Sydkorea faar landsdaekkende netvaerk til 'tingenes internet', 2016. available at http://goo.gl/ KQJnKz

[25] J. S. W. Giezeman.

[26] R. Giffinger. Smart cities Ranking of European mediumsized cities. October, 16(October):13-18, 2007.

[27] J. M. Gutierrez, M. Jensen, M. Henius, and T. Riaz. Smart Waste Collection System Based on Location Intelligence. Procedia Computer Science, 61:120-127, 2015.

[28] I. Hong, S. Park, B. Lee, J. Lee, D. Jeong, and S. Park. Iotbased smart garbage system for efficient food waste management. The Scientific World Journal, 2014, 2014.

[29] R. Jalali, K. El-khatib, and C. McGregor. Smart city architecture for community level services through the internet of things. 2015 18th International Conference on Intelligence in Next Generation Networks, pages 108-113, 2015. 
[30] G. Kuk and M. Janssen. The business models and information architectures of smart cities. Journal of Urban Technology, 18(2):39-52, 2011.

[31] B. Latour. Science in action: How to follow scientists and engineers through society. Harvard university press, 1987.

[32] M. Lawrance and E. Woods. Advanced collection, processing, energy recovery, and disposal technologies for the municipal solid waste value chain: Global market analysis and forecasts, 2014.

[33] D. Lee, D. Offenhuber, a. Biderman, and C. Ratti. Learning from tracking waste: How transparent trash networks affect sustainable attitudes and behavior. Internet of Things (WFIoT), 2014 IEEE World Forum on, pages 130-134, 2014.

[34] Manuel Pedro Rodríguez-Bolívar. Smart Cities: Big Cities, Complex Governance? Public administration and information technology, (8), 2015.

[35] A. Medvedev, P. Fedchenkov, A. Zaslavsky, T. Anagnostopoulos, and S. Khoruzhnikov. Waste management as an iot-enabled service in smart cities. In Conference on Smart Spaces, pages 104-115. Springer, 2015.

[36] P. Neirotti, A. De Marco, A. C. Cagliano, G. Mangano, and F. Scorrano. Current trends in smart city initiatives: Some stylised facts. Cities, 38:25-36, 2014.

[37] A. Nissen. Smarte skraldespande hjaelper miljoeet, 2015. available at http://goo.gl/e7Rtt0

[38] T. Nuortio, J. Kytöjoki, H. Niska, and O. Bräysy. Improved route planning and scheduling of waste collection and transport. Expert systems with applications, 30(2):223-232, 2006.

[39] A. Picon. Smart Cities: A Spatialised Intelligence. 1st edition, 2015.

[40] J. A. Poss, J. T. Satwicz, and D. J. Skocypec. Electricallypowered programmable waste enclosure, July 21 2011. US Patent App. 13/812,173.

[41] R. R. Sanseverino. Competitive Urban Models. 2014.

[42] R. R. Sanseverino and S. Orlando. The Integration and Sharing of Resources for a New Quality of Living. Sxl-Springer for Innovation, (12), 2014.

[43] T. Thorlin. Solen skinner og skraldet flyder i koebenhavn - mx.dk, 2016. available at http://www.mx.dk/ nyheder/kobenhavn/story/18498138.

[44] K. T. Ulrich. Product design and development. Tata McGraw-Hill Education, 2003.

[45] B. Van Bastelaer. Digital cities and transferability of results. In the proceedings of the 4th EDC Conference on Digital Cities, Salzburg, October, pages 29-30, 1998.

[46] E. P. Weber and A. M. Khademian. Wicked problems, knowledge challenges, and collaborative capacity builders in network settings. Public administration review, 68(2):334349, 2008.

[47] C. Winstrom. Skraldet flyder i koebenhavn, 2016. available at http://www.b.dk/nationalt/ skraldet-flyder-i-koebenhavn

[48] D. C. Wyld. Taking out the trash (and the recyclables): Rfid and the handling of municipal solid waste. International Journal Of software Engineering \& Applications (IJSEA), 1(1):1-13, 2010. 